\title{
Crescimento, Conversão Alimentar e Rendimento de Carcaça de Bezerros da Raça Holandesa Alimentados com Dietas Contendo Diferentes Níveis de Volumoso ${ }^{1}$
}

\author{
Ricardo Dias Signoretti ${ }^{2}$, José Fernando Coelho da Silva ${ }^{3}$, Sebastião de Campos Valadares Filho ${ }^{3}$, \\ José Carlos Pereira ${ }^{3}$, Gherman Garcia Leal de Araújo5, Paulo Roberto Cecon 4 , \\ Augusto César de Queiroz ${ }^{3}$, Elaine B. Muniz ${ }^{6}$
}

\begin{abstract}
RESUMO - Este trabalho foi conduzido para avaliar o efeito dos diferentes níveis de volumoso nas dietas sobre o consumo médio diário de matéria seca total (CDMST), o ganho médio de peso, a conversão alimentar e o rendimento de carcaça. Trinta e seis bezerros da raça Holandesa puros por cruzamento, com idade média de 60 dias e peso vivo (PV) inicial de $78 \mathrm{~kg}$, foram distribuídos em delineamento inteiramente casualizado. Os animais foram alimentados à vontade com dietas contendo níveis de 10, 25, 40 e 55\% de volumoso, na base da MS, usando-se feno de capim coast-cross (Cynodon dactylon), fubá de milho e farelo de soja, os quais constituíram dietas com aproximadamente $16 \%$ de PB. Os animais foram pesados a cada periodo de 28 dias, com pesagens mais freqüentes para os animais que se aproximavam dos pesos de abate pré-estabelecidos, de $190 \pm 10 \mathrm{~kg}$ e $300 \pm 10 \mathrm{~kg}$, para os grupos 1 e 2 , respectivamente. O consumo de matéria seca não foi influenciado pelos níveis de volumoso nas dietas para ambos os grupos. Houve efeito linear crescente para conversão alimentar expressa em PV e peso corporal vazio (PCVZ). Os ganhos médios de peso diários expressos em PV e PCVZ decresceram linearmente, em função dos níveis de volumoso nas dietas. O peso da carcaça quente e o rendimento de carcaça quente para os animais de grupo 2 não foram influenciados, enquanto o rendimento de carcaça quente dos animais do grupo 1 decresceu linearmente, com o aumento de volumoso nas dietas. Os ganhos médios de pesos diários aos 28 e 56 dias, para o grupo 1, e aos 28, 56, 84 e 112 dias, para o grupo 2, reduziram linearmente com a elevação dos níveis de volumoso nas dietas. O desempenho dos bezerros de ambos os grupos de abate foi maior com uso de menores níveis de volumoso na dieta, porém, acima de 5 meses de idade, o uso de maiores níveis de volumoso não acarretou prejuízos à performance dos animais.
\end{abstract}

Palavras-chave: bezerro holandês, conversão alimentar, desempenho, feno

\section{Growth, Feed:Gain Ratio and Carcass Yield of Holstein Calves Fed Diets with Different Levels of Forage}

\begin{abstract}
This work was conducted aiming to evaluate the effect of different forage levels in the diet on the average daily dry matter intake (DMI), average weight gain (AWG), feed:gain ratio and carcass yield. Thirty-six pure Holstein bull calves, 60 days old with initial average live weight ( $\mathrm{LW}$ ) of $78 \mathrm{~kg}$, were allotted in a completely randomized experimental design. The animals were ad libitum fed with diets contained 10,25, 40, and 55\% of forage, on the DM basis, using chopped coast-cross (Cynodon dactylon) grass, ground corn and soybean meal, which constitute diets with approximately $16 \% \mathrm{CP}$. Animals were weighed at each 28 days period, with more frequent weighing for the animals near to the pre stabilized slaughtering weights of $190 \pm 10$ and $300 \pm 10 \mathrm{~kg}$, for the groups 1 and 2 , respectively. Forage levels of the diet for both groups did not affect the dry matter intake. There was increased linear effect of forage level on feed:gain ratio expressed as LW or empty body weight (EBW). The average weight gain expressed in LW and EBW decreased linearly in function of the levels of forage in the diet. The hot carcass weight and hot carcass dressing for animals in group 2 were not affected, while the hot carcass dressing of animals from group 1 decreased linearly with the level of forage in the diet. The average daily gain at 28 and 56 days for group 1 and at 28, 56, 84 and 112 days for group 2, reduced linearly with the increasing of forage levels in the diets. The animal performance for both groups was higher with the use of low levels of forage in the diets, but above five months of age, the use of higher forage levels was not harmful to the performance of the animals.
\end{abstract}

Key Words: Holstein calf, feed:gain ratio, performance, hay

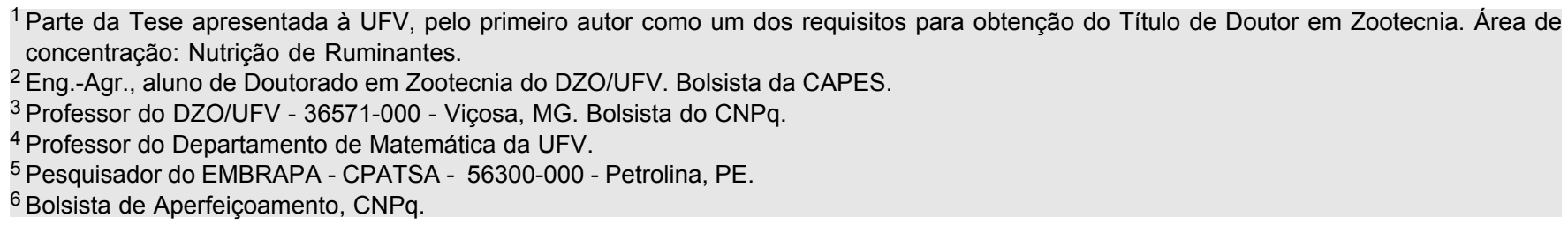




\section{Introdução}

O mundo atual está sofrendo profundas modificações de cunho geoeconômico. Além disso, a exigência referente ao padrão de vida da população, imposta pela sociedade moderna, está alterando significativamente os hábitos alimentares das pessoas, o que tem provocado alterações irreversíveis sobre a produção e o mercado de alimentos.

Dentro deste contexto, a crescente demanda de carne bovina de melhor qualidade, aliada aos índices de produtividade insatisfatórios, e a queda na lucratividade no setor pecuário serão em breve fatores determinantes das mudanças nos principais segmentos do complexo pecuário brasileiro.

Desse modo, os produtores de leite, cujas propriedades estão localizadas nas proximidades dos grandes centros consumidores, terão que se estruturar para criar e recriar os machos da raça Holandesa para produção de carne, contribuindo, assim, para melhorar o índice de desfrute do rebanho nacional.

O grande problema é que os bezerros da raça Holandesa não conseguem se adaptar às condições rústicas de um sistema de criação mais extensivo, sendo conseqüentemente, em sua grande maioria, vendidos o mais cedo possível após o nascimento e abatidos para fabricação de embutidos ou criados sob condições adversas, resultando em elevados índices de morbidade e mortalidade; aqueles que sobrevivem são abatidos acima dos 4 anos de idade (LUCCI, 1989; CAMPOS, 1994).

A eliminação pura e simples dos machos da raça Holandesa, que são vendidos para a indústria, com peso entre 35 e $40 \mathrm{~kg}$, pelo preço máximo de $\mathrm{R} \$ 10,00$ por cabeça, com a finalidade de poupar leite, mão-deobra, medicamentos, dentre outros, acarretará enorme prejuízo aos produtores de leite. Contudo, a criação de bezerros da raça Holandesa dentro de esquema econômico não é tarefa simples. O grande entrave é a fase de aleitamento, pois inclui-se entre uma das mais críticas e onerosas na criação de bezerros. No entanto, inúmeras pesquisas foram conduzidas no Brasil e no exterior procurando melhorar a eficiência dos sistemas de manejo e alimentação, a ambientação e a sanidade destes animais. Dentre as tecnologias desenvolvidas, a prática do desaleitamento precoce, a utilização de sucedâneo de leite idôneo, a mão-deobra mais especializada e a alimentação à base de volumoso e concentrados de boa qualidade a baixo custo contemplam os bezerros da raça Holandesa a serem recriados para produção de carne, em idades mais precoces (CAMPOS e SILVA, 1986; LUCCI, 1989; CAMPOS et al., 1991; CAMPOS e LIZIEIRE, 1992; MATOS, 1992; LUCCI, 1992; e SIGNORETTI et al., 1995, 1997).

Com relação ao aproveitamento de bezerros da raça Holandesa para produção de carne, as pesquisas no Brasil são escassas; as existentes relataram que estes animais apresentaram bom potencial como produtores de carne, em face dos resultados obtidos quanto ao rendimento de carcaça e à excelente qualidade da carne (BIONDI et al., 1984; LUCCI, 1989; e CAMPOS et al., 1996). Por conseguinte, não parece recomendável o abate de machos da raça Holandesa ao nascer, sendo preferível recriá-los sob quantidades limitadas de leite. Quando estiverem aptos a entrarem no confinamento, devem ser abatidos precocemente, utilizando adequada proporção volumoso e concentrado na dieta, possibilitando assim minimizar o custo de produção e maximizar a eficiência biológica para produção de carne. Isto contribuirá para incrementar a produção de carne de boa qualidade a baixo custo e, conseqüentemente, melhorar a rentabilidade dos pecuaristas de leite.

Desse modo, nas condições peculiares de um país de clima tropical, pesquisas devem ser intensificadas na busca de alternativas de sistemas de manejo e alimentação eficientes para o aproveitamento do grande potencial dos machos da raça Holandesa para produção de carne.

Entre essas pesquisas, CAMPOS et al. (1996) estudaram o desenvolvimento de 18 machos da raça Holandesa do nascimento aos 6 meses de idade, quando foram abatidos pesando aproximadamente $200 \mathrm{~kg}$. Os animais foram alimentados com quantidades liberais de concentrado. Foram obtidos ganhos médios diários de peso de 0 a $49(351 \pm 37 \mathrm{~g}), 49$ a 182 $(1046 \pm 37 \mathrm{~g})$ e 0 a 182 dias de idade $(859 \pm 37 \mathrm{~g})$. O rendimento médio de carcaça quente foi de 52,36\%.

BIONDI et al. (1984) relataram que bezerros da raça Holandesa apresentaram bom potencial como produtores de carne, em face da grande velocidade de ganho de peso. O sistema de alimentação utilizado foi o confinamento no inverno, em que os animais receberam 3,0 kg de concentrado por dia e feno de capim-gordura à vontade e no verão, pastagem de capim-jaraguá. Os ganhos médios diários de peso foram de 0,$587 ; 0,337 ; 0,718$; e $0,659 \mathrm{~kg}$ para os períodos de $6,12,18$ e 24 meses de idade, respectivamente. Os autores concluíram que os animais obtiveram maior ganho de peso quando confinados.

Segundo LUCCI (1989), os bezerros da raça 
Holandesa puros ou de alta cruza poderiam ser criados até aos 6 meses de idade em boxes coletivos, recebendo $2,5 \mathrm{~kg}$ de concentrado por dia e volumoso à vontade, praticando-se o desaleitamento aos 60 dias. Os ganhos diários de peso seriam de $0,5 \mathrm{~kg}$ até 91 dias de idade. Dessa forma, o animal deverá chegar aos 6 meses com $145 \mathrm{~kg}$ de peso vivo, em média.

BROSH et al. (1995) estudaram os efeitos de dietas com concentrações de energia metabolizável de 10,$0 ; 10,9$; e $11,7 \mathrm{MJ} / \mathrm{kg}$ de MS sobre a taxa de crescimento de machos da raça Holandesa, com idade média de 180 dias e peso vivo inicial de $200 \mathrm{~kg}$. Os ganhos médios de peso vivo $(\mathrm{kg} / \mathrm{dia})$ foram de 0,$93 ; 1,06$; e 1,16, respectivamente.

FLUHARTY et al. (1994) avaliaram os efeitos de dietas ricas em energia ( $70 \%$ de concentrado) e com baixo nível de energia ( $45 \%$ de concentrado), sobre desempenho de novilhos mestiços (peso vivo inicial de $237 \mathrm{~kg}$ ). Os autores verificaram ganho médio diário de peso de $1,19 \mathrm{~kg}$ para animais recebendo ambas as dietas, porém, a eficiência alimentar ( $\mathrm{kg}$ de ganho/ $\mathrm{kg}$ de alimento) foi de 0,213 e 0,196 para dieta com 70 e $45 \%$ de concentrado, respectivamente. Concluiu-se que as dietas contendo $70 \%$ foram de melhor eficiência alimentar $(8,7 \%) \mathrm{em}$ relação àquelas contendo $45 \%$ de concentrado.

O confinamento é uma tecnologia que possibilita o abate de animais jovens e a obtenção de carcaça e carne de melhor qualidade (MOLLETTA e RESTLE, 1996), porém, no Brasil, ainda não se pratica a adequada remuneração pela qualidade de carcaça e carne. Contudo, o ganho de peso de bovinos em confinamento é influenciado pelo nível nutricional. Na literatura encontram-se resultados mostrando melhor desempenho com dietas contendo maior porcentagem de concentrado (PRESTON e WILLIS, 1974). No entanto, o concentrado, pelo seu elevado conteúdo energético, é a porção responsável pelo crescimento e pela engorda dos animais, porém, é também um dos constituintes mais onerosos nos custos operacionais de um confinamento (FEIJÓ et al., 1996a,b).

A determinação da proporção ótima de volumoso e concentrado na dieta de bezerros da raça Holandesa confinados, aliada à avaliação da ingestão de nutrientes, da conversão alimentar, do ganho de peso e do rendimento de carcaça, serão de grande importância para produção de carne de melhor qualidade, proporcionando aumento da produtividade e lucratividade do confinamento (EUCLIDES FILHO et al., 1997).

O objetivo deste trabalho foi avaliar o efeito de diferentes níveis de volumoso nas dietas sobre o consumo total de MS, o ganho de peso vivo, o ganho de peso corporal vazio, a conversão alimentar e o rendimento de carcaça de 36 bezerros da raça Holandesa puros por cruzamento, em confinamento.

\section{Material e Métodos}

O local, o período de realização, o manejo dos animais e as dietas utilizadas neste experimento foram descritos por SIGNORETTI et al. (1999).

Foram utilizados 36 bezerros da raça Holandesa puros por cruzamento, sendo 20 para o grupo 1 ( $190 \pm 10 \mathrm{~kg}$ de peso vivo ao abate) e 16 para o grupo 2 (300 $\pm 10 \mathrm{~kg}$ de peso vivo ao abate), alimentados $a d$ libitum e distribuídos aleatoriamente nos tratamentos, sendo cinco e quatro repetições por tratamento para o grupo 1 e 2, respectivamente. As dietas tiveram níveis crescentes de volumoso (feno de capim coast-cross, Cynodon dactylon): 10; 25; 40; e 55\%, que constituíram os tratamentos 1, 2, 3 e 4, respectivamente.

Para determinação do ganho de peso vivo e do peso corporal vazio, da conversão alimentar e dos rendimentos de carcaça, foram realizadas pesagens ao início do experimento, com idade média de 60 dias, ou seja, após o desaleitamento, sendo os bezerros submetidos a 15 dias de adaptação às dietas e pesados por dois dias consecutivos: no primeiro dia considerou-se o peso vivo inicial e no segundo dia, após jejum de 16 horas, o peso inicial de jejum. A cada período de 28 dias, todos os animais foram pesados, após jejum de 16 horas, adotando-se pesagens intermediárias para aqueles que se aproximavam dos pesos de abate pré-estabelecidos de $190 \pm 10 \mathrm{~kg}$ e $300 \pm 10 \mathrm{~kg}$, para os grupos 1 e 2, respectivamente.

O consumo diário das dietas fornecidas e das sobras, para cada animal, foi registrado para a determinação do consumo total de MS e da conversão alimentar. Além disso, foram realizadas amostragens semanais dos concentrados e do feno e diárias de sobras. Ao final de cada período de 28 dias, foram feitas amostras compostas do material, as quais foram armazenadas em vidros com tampas de polietileno, devidamente identificados e guardados em congelador, para análises posteriores.

Ao atingirem os pesos pré-estabelecidos de $190 \pm 10 \mathrm{~kg}$ (grupo 1) e $300 \pm 10 \mathrm{~kg}$ (grupo 2), os animais foram abatidos. Antes de serem abatidos, os animais foram submetidos a período de jejum de 16 horas, com acesso à água. $\mathrm{O}$ abate foi feito por concussão cerebral e secção da veia jugular. Os 
pesos do sangue, da cabeça, do couro, dos pés, da cauda, do rúmen-retículo, do omaso, do abomaso, dos intestinos delgado e grosso, do mesentério, da gordura interna, do fígado, do coração, dos rins, do baço, do pulmão, da língua, do esôfago, da traquéia e do aparelho reprodutor foram registrados. As carcaças dos animais foram divididas em duas metades, que foram pesadas individualmente, obtendo-se o peso da carcaça quente (PCQ). O peso do corpo vazio final (PCVZF) dos animais foi obtido pela soma dos pesos da carcaça, do sangue, da cabeça, do couro, dos pés, da cauda, das vísceras e dos órgãos. A porcentagem de rendimento da carcaça quente (\% RCQ) foi determinada pelo peso da carcaça quente dividido pelo peso após jejum multiplicado por 100 .

Utilizou-se o delineamento experimental inteiramente casualizado, com quatro tratamentos e cinco e quatro repetições para os grupos 1 e 2 , respectivamente. Realizaram-se análises de variância e regressão na interpretação das variáveis estudadas, usando-se o programa computacional SAEG. Os coeficientes de regressão foram comparados pelo teste " $t$ ", adotando-se os níveis de 1 e $5 \%$ de probabilidade.

\section{Resultados e Discussão}

Os dados referentes às médias, os coeficientes de variação e as equações de regressão para consumo médio diário de matéria seca total (CDMST), ganho de peso vivo (GDPV), ganho diário de peso corporal vazio (GDPCVZ), conversão alimentar em relação ao peso vivo (CAPV) e ao peso corporal vazio (CAPCVZ), número de dias de confinamento (NDC), peso corporal vazio final (PCVZF), peso da carcaça quente (PCQ) e porcentagem de rendimento de carcaça quente (RCQ), em função dos níveis de volumoso nas dietas, para os animais do grupo 1 (190 $\mathrm{kg}$ de PV) e grupo2 (300 kg de PV), encontram-se, respectivamente, nas Tabelas 1 e 2 .

Os consumos diários de MS total não foram influenciados pelo níveis de volumoso nas dietas, para os animais dos grupos 1 e 2. Observou-se consumo médio diário de MS de 4,01 e 5,26 kg, respectivamente, para os animais dos grupos 1 e 2. Em estudo semelhante, ARAÚJO (1997) verificou que os níveis de volumoso na dieta proporcionaram respostas curvilíneas para o consumo de MS, para animais de $300 \mathrm{~kg}$ de $\mathrm{PV}$, enquanto os consumos dos animais abatidos com $180 \mathrm{~kg}$ de PV não foram influenciados pelos níveis de volumoso. FEIJÓ et al. (1996a,b) também não verificaram efeito de diferentes propor- ções de volumoso:concentrado na ração sobre o consumo de MS (kg/dia), em animais mestiços $\mathrm{F}_{1}$ Pardo Suíço x Nelore e Nelore confinados, em fase final de crescimento. Por outro lado, FERREIRA (1997), trabalhando com animais mestiços $F_{1}$ Simental $x$ Nelore confinados, em fase final de crescimento, verificou efeito linear crescente com adição de concentrado nas rações.

Observou-se comportamento linear crescente ( $\mathrm{P}<0,01)$, para CAPV $(3,36$ a $4,21 \mathrm{~kg} / \mathrm{kg}$ de ganho) e CAPCVZ (3,82 a $5,38 \mathrm{~kg} / \mathrm{kg}$ de ganho), para os animais abatidos com $190 \mathrm{~kg}$ de PV, em função dos níveis de volumoso. De forma semelhante, para os animais de $300 \mathrm{~kg}$ de $\mathrm{PV}$, foi verificado o mesmo comportamento para CAPV $(4,31$ a $5,38 \mathrm{~kg} / \mathrm{kg}$ de ganho) e CAPCVZ (4,81 a $6,37 \mathrm{~kg} / \mathrm{kg}$ de ganho).

Verificou-se melhor eficiência de utilização de alimentos em todos os níveis de volumoso estudados para os bezerros abatidos aos $190 \mathrm{~kg}$, em comparação àqueles abatidos aos $300 \mathrm{~kg}$. No entanto, a CAPV e a CAPCVZ foram melhores para as dietas com menor nível de volumoso.

Resultados semelhantes foram obtidos por ARAÚJO (1997), estudando o efeito de diferentes níveis de volumoso na ração de bezerros mestiços Holandês $\mathrm{x}$ Zebu, porém, os valores médios obtidos para CAPV e CAPCVZ foram 7,01 e 10,75\% inferiores, respectivamente, aos encontrados neste trabalho, os quais confirmam o grande potencial de bezerros da raça Holandesa confinados em converter os alimentos ingeridos em ganho de peso eficientemente.

FLUHARTY et al. (1994), FEIJÓ et al. (1996a,b), EUCLIDES FILHO et al. (1997) e FERREIRA (1997) também verificaram melhor conversão alimentar com adição de concentrado na ração de bovinos confinados.

Houve efeito linear decrescente $(\mathrm{P}<0,01)$ para $\operatorname{GDPV}(1,23$ a $0,92 \mathrm{~kg})$ e $\operatorname{GDPCVZ}(1,08$ a $0,72 \mathrm{~kg})$, para os animais do grupo 1 (Tabela 1), e para GDPV $(1,16$ a $0,96 \mathrm{~kg})$ e $\operatorname{GDPCVZ}(1,04$ a $0,81 \mathrm{~kg})$, para os animais do grupo 2 (Tabela 2), em função dos níveis de volumoso. Resultados similares foram obtidos por ARAÚJO (1997), em animais na faixa de $180 \mathrm{~kg}$ de $\mathrm{PV}$, porém os ganhos tanto de peso vivo como de peso corporal vazio foram inferiores aos encontrados neste trabalho. Por outro lado, para animais de $300 \mathrm{~kg}$ de $P V$, esse autor não verificou efeito dos níveis de volumoso sobre GDPV e GDPCVZ, todavia, os ganhos médios obtidos de 860 e $730 \mathrm{~g} /$ dia foram inferiores aos obtidos no presente trabalho (1090 e $955 \mathrm{~g} /$ dia, respectivamente).

BARTLE et al. (1994), BROSH et al. (1995), 
Rev. bras. zootec.

Tabela 1- Médias e equações de regressão ajustadas (ER) para consumo diário de matéria seca total (CDMST), ganho diário de peso vivo (GDPV) e de peso corporal vazio (GDPCVZ), conversão alimentar em relação ao peso vivo (CAPV) e ao peso corporal vazio (CAPCVZ), número de dias de confinamento (NDC), peso corporal vazio final (PCVZF) peso de carcaça quente (PCQ) e porcentagem de rendimento de carcaça (RCQ) para animais do grupo 1 (190 kg de PV)

Table 1 - Means and fitted regression equations (RE) for total daily dry matter intake (DTDMI), daily weight gain (DWG) and empty body weight gain (DEBWG), feed:gain ratio in relation to live weight ( $F: G L W$ ) and empty body weight (F:GEBW), number of days of feedlot (NDF), final empty body weight (FEBW), hot carcass weight (HCW) and carcass dressing percentage (CDP) for animals of the group 1 $(190 \mathrm{~kg}$ of $L W)$

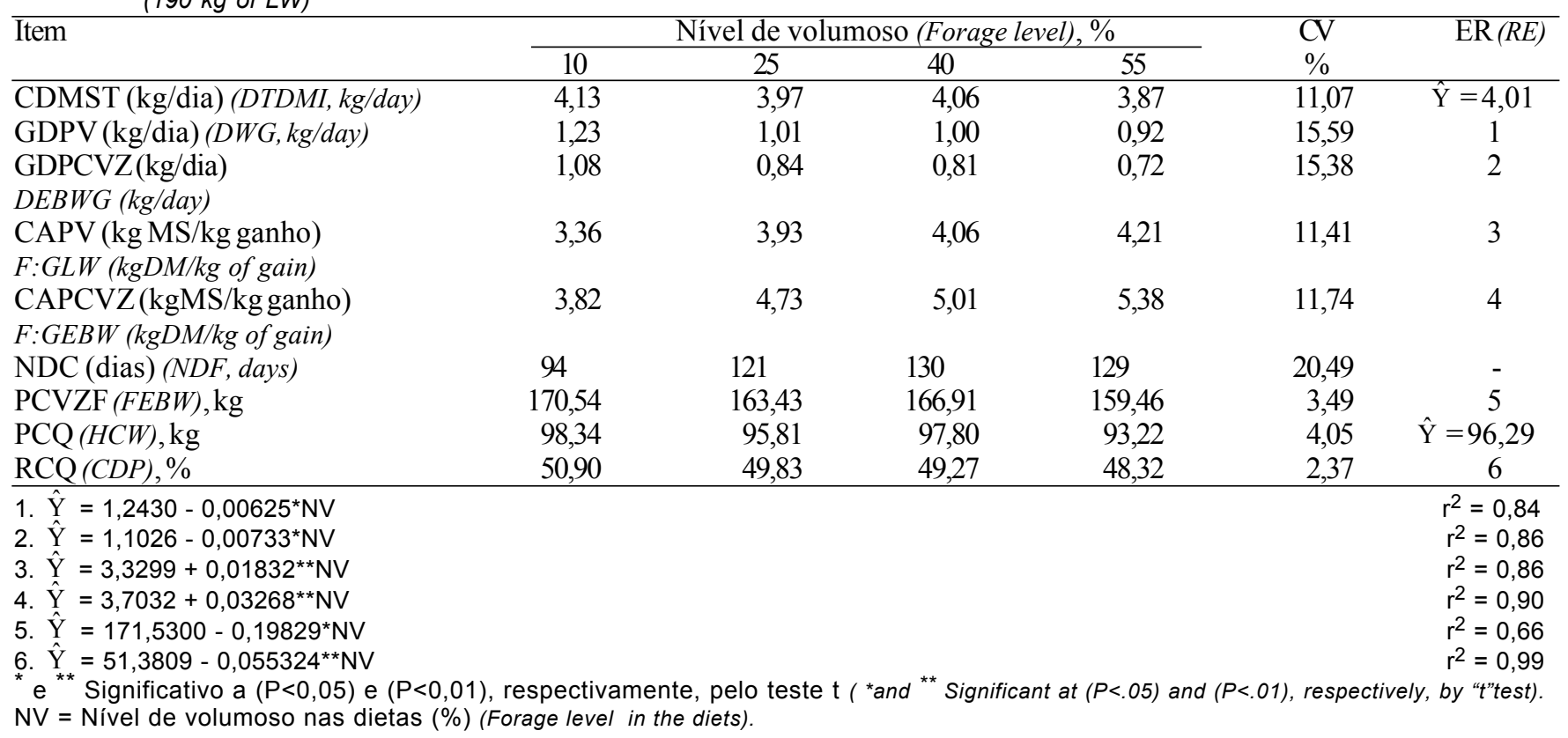

Tabela 2 - Médias e equações de regressão ajustadas (ER), para consumo diário de matéria seca total (CDMST), ganho diário de peso vivo (GDPV) e de peso corporal vazio (GDPCVZ), conversão alimentar em relação ao peso vivo (CAPV) e ao peso corporal vazio (CAPCVZ), número de dias de confinamento (NDC), peso corporal vazio final (PCVZF) peso de carcaça quente (PCQ) e porcentagem de rendimento de carcaça (RCQ) para animais do grupo 2 (300 kg de PV)

Table 2 - Means and fitted regression equations (RE) for daily total dry matter intake (DTDMI), daily live weight gain (DWG) and empty body weight gain (DEBWG), feed:gain ratio in relation of live weight ( $F: G L W$ ) and empty body weight ( $F: G E B W)$, number of days of feedlot (NDF), final empty body weight (FEBW), hot carcass weight (HCW) and carcass dressing percentage (CDP) for animals of group $2(300 \mathrm{~kg}$ of $L W)$

\begin{tabular}{|c|c|c|c|c|c|c|}
\hline$\overline{\text { Item }}$ & & el de vo & o (Fora & & $\mathrm{CV}$ & $\mathrm{ER}(R E)$ \\
\hline & 10 & 25 & 40 & 55 & $\%$ & \\
\hline CDMST (kg/dia) (DTDMI, kg/day) & 5,00 & 5,31 & 5,58 & 5,16 & 9,06 & $\hat{Y}=5,26$ \\
\hline GDPV (kg/dia) (DWG, kg/day) & 1,16 & 1,18 & 1,06 & 0,96 & 15,70 & 1 \\
\hline GDPCVZ (kg/dia) (DEBWG, $\mathrm{kg} /$ day $)$ & 1,04 & 1,04 & 0,93 & 0,81 & 15,42 & 2 \\
\hline CAPV (kg MS/kg ganho) & 4,31 & 4,50 & 5,26 & 5,38 & 9,35 & 3 \\
\hline$F / G L W(\mathrm{kgDM} / \mathrm{kg}$ of gain $)$ & & & & & & \\
\hline CAPCVZ (kg MS/kg ganho) & 4,81 & 5,11 & 6,00 & 6,37 & 9,14 & 4 \\
\hline$F / G E B W(\mathrm{kgDM} / \mathrm{kg}$ of gain) & & & & & & \\
\hline NDC (dias) (NDF, days) & 199 & 188 & 211 & 229 & 17,80 & - \\
\hline $\operatorname{PCVZF}(F E B W), \mathrm{kg}$ & 269,25 & 268,07 & 268,90 & 255,97 & 2,24 & 5 \\
\hline $\mathrm{PCQ}(H C W), \mathrm{kg}$ & 159,98 & 158,68 & 161,33 & 152,08 & 3,34 & $\hat{Y}=158,01$ \\
\hline $\mathrm{RCQ}(C D P), \%$ & 52,95 & 52,16 & 52,58 & 50,74 & 3,13 & $\hat{\mathrm{Y}}=52,11$ \\
\hline 1. $\hat{Y}=1,2444-0,00474^{*} \mathrm{NV}$ & & & & & & $r^{2}=0,83$ \\
\hline 2. $\hat{Y}=1,1245-0,005331^{*} \mathrm{NV}$ & & & & & & $r^{2}=0,88$ \\
\hline 3. $\hat{Y}=4,1025+0,02466^{*} \mathrm{NV}$ & & & & & & $\mathrm{r}^{2}=0,92$ \\
\hline 4. $\hat{Y}=4,4844+0,03549^{* *} \mathrm{NV}$ & & & & & & $r^{2}=0,97$ \\
\hline 5. $\hat{\mathrm{Y}}=273,9970-0,26000^{*} \mathrm{NV}$ & & & & & & $r^{2}=0,62$ \\
\hline
\end{tabular}


GOMES e ANDRADE (1996) e FERREIRA (1997) também observaram maiores ganhos de peso com adição de concentrado na ração de bovinos em crescimento confinados.

O PCVZF (kg) para os animais dos grupos 1 e 2 apresentaram comportamento linear decrescente $(\mathrm{P}<0,05)$, em função dos níveis de volumoso, em virtude, provavelmente, do maior conteúdo do trato gastrointestinal em animais que receberam ração com maior nível de volumoso. ARAÚJO (1997) verificou comportamento similar em animais de faixa de peso semelhante.

Com relação ao peso da carcaça quente $(\mathrm{kg})$, não foram evidenciados efeitos dos níveis de volumoso, para animais dos grupos 1 e 2, os quais apresentaram PCQ médio de 96,29 e 158,01 kg, respectivamente. No entanto, mesmo não havendo diferenças entre os níveis de volumoso, observou-se tendência de menor PCQ em animais que receberam 55\% de volumoso na dieta, provavelmente devido ao menor ganho de peso, à pior conversão alimentar e ao maior conteúdo do trato gastrointestinal. ARAÚJO (1997), em trabalho semelhante, verificou efeito linear decrescente no PCQ, em função dos níveis de volumoso na dieta, em animais de faixa de peso semelhante. Por outro lado, o RCQ em animais do grupo $1(190 \mathrm{~kg})$ apresentou comportamento linear decrescente $(\mathrm{P}<0,01)$, enquanto os animais do grupo $2(300 \mathrm{~kg})$ não foram influenciados pelos níveis de volumoso na dieta.

O aumento da proporção de concentrado na dieta de bovinos em confinamento tende a melhorar o rendimento de carcaça, em virtude da redução do conteúdo gastrointestinal (PRESTON e WILLIS, 1974). Todavia, quase não foram verificadas diferenças entre as proporções de volumoso:concentrado, na dieta de bovinos sobre o peso e o rendimento de carcaça quente, quando o período de jejum e o peso de abate foram pré-determinados (GEAY, 1975; PETIT et al., 1994).

Os valores médios para RCQ foram de 49,58 e $52,11 \%$, respectivamente, para animais abatidos com 190 e $300 \mathrm{~kg}$ de peso vivo. Resultados próximos foram obtidos por CAMPOS et al. (1996), que verificaram rendimento médio de carcaça quente de $52,36 \%$ em animais machos da raça Holandesa aos 6 meses de idade, abatidos com $200 \mathrm{~kg}$ de peso vivo, e também por ARAÚJO (1997), que verificou valores médios para RCQ de 49,85 e $53,25 \%$ em bezerros mestiços Holandês x Zebu, abatidos com 180 e $300 \mathrm{~kg}$ de peso vivo, respectivamente.

Nas Tabelas 3 e 4, são apresentadas as médias de consumo de feno, concentrado, dias de confinamento e custo de produção, por nível de volumoso na dieta, de bezerros da raça Holandesa abatidos com 190 e $300 \mathrm{~kg}$ de peso vivo (PV), respectivamente.

Observaram-se, em animais abatidos com $190 \mathrm{~kg}$ de PV, ganhos de peso mais elevados, quando a dieta continha menor nível de volumoso, e conseqüentemente menor tempo de permanência dos animais no confinamento, resultando em menor custo por arroba (R\$ 20,20/arroba) para animais alimentados com dietas contendo $10 \%$ de volumoso (Tabela 3 ).

Com relação aos animais abatidos com $300 \mathrm{~kg}$ de $\mathrm{PV}$, verificou-se maior produção de arrobas, em animais alimentados com dietas contendo $40 \%$ de volumoso (Tabela 4). Contudo, o menor custo de produção por arroba foi encontrado para animais que permaneciam por menor tempo no confinamento (188 dias) e, conseqüentemente, menor custo por arroba $(\mathrm{R} \$ 25,74)$.

A viabilização do aproveitamento de bezerros da raça Holandesa para produção de carne dependerá, principalmente, dos empresários que se especializem nesta atividade e do trabalho de valorização da carcaça e abertura de mercado para o produto, pois os matadouros preferem abater animais mais pesados, os consumidores não valorizam este tipo de carne e em razão de seu preço ser o mesmo de qualquer outra carcaça de carne vermelha (CAMPOS et al., 1996).

Além disso, na prática, a qualidade e o preço do volumoso e do concentrado utilizados na alimentação devem ser analisados, procurando sempre maximizar a produtividade e a lucratividade.

Os dados referentes às médias, aos coeficientes de variação e às equações de regressão ajustadas, para ganho de peso médio diário (GPD) a cada período de 28 dias, para os animais dos grupos 1 e 2 , encontram-se, respectivamente, nas Tabelas 5 e 6 . Observou-se comportamento linear decrescente para GP0 - $28(1,22$ a 0,57 kg) e GP28 - $56(1,26$ a 0,89 kg) no grupo 1 (190 kg de PV) e para GP0 - 28 (1,06 a 0,73 $\mathrm{kg})$, GP2 8 - 56 (1,31 a 0,81 kg), GP56 - 84 (1,31 a 0,95 $\mathrm{kg})$ e GP84 - $112(1,28$ a $0,92 \mathrm{~kg})$ para o grupo 2 (300 $\mathrm{kg}$ de $\mathrm{PV}$ ), em função dos níveis de volumoso nas dietas. Em princípio, este fato pode ser explicado pelo menor consumo de nutrientes digestíveis totais pelos animais, de ambos os grupos, com o aumento do nível de volumoso na dieta. O consumo de energia exerce controle sobre a taxa de crescimento e a composição corporal; deste modo, a redução da ingestão de energia, geralmente, causará depressão na taxa de crescimento, verificando-se efeito mais pronunciado sobre a taxa de desenvolvimento do tecido adiposo e deposição de lipídeos, em animais de maturidade 
Rev. bras. zootec.

Tabela 3 - Médias de consumo de feno e concentrado, dias de confinamento (DC) e custo de produção por nível de volumoso na dieta de bezerros Holandeses abatidos com $190 \mathrm{~kg}$ de peso vivo

Table 3 - Means of hay and concentrate intake, days of feedlot (DF) and production cost by forage level in the diet of Holstein calves slaughtered at $190 \mathrm{~kg}$ of live weight

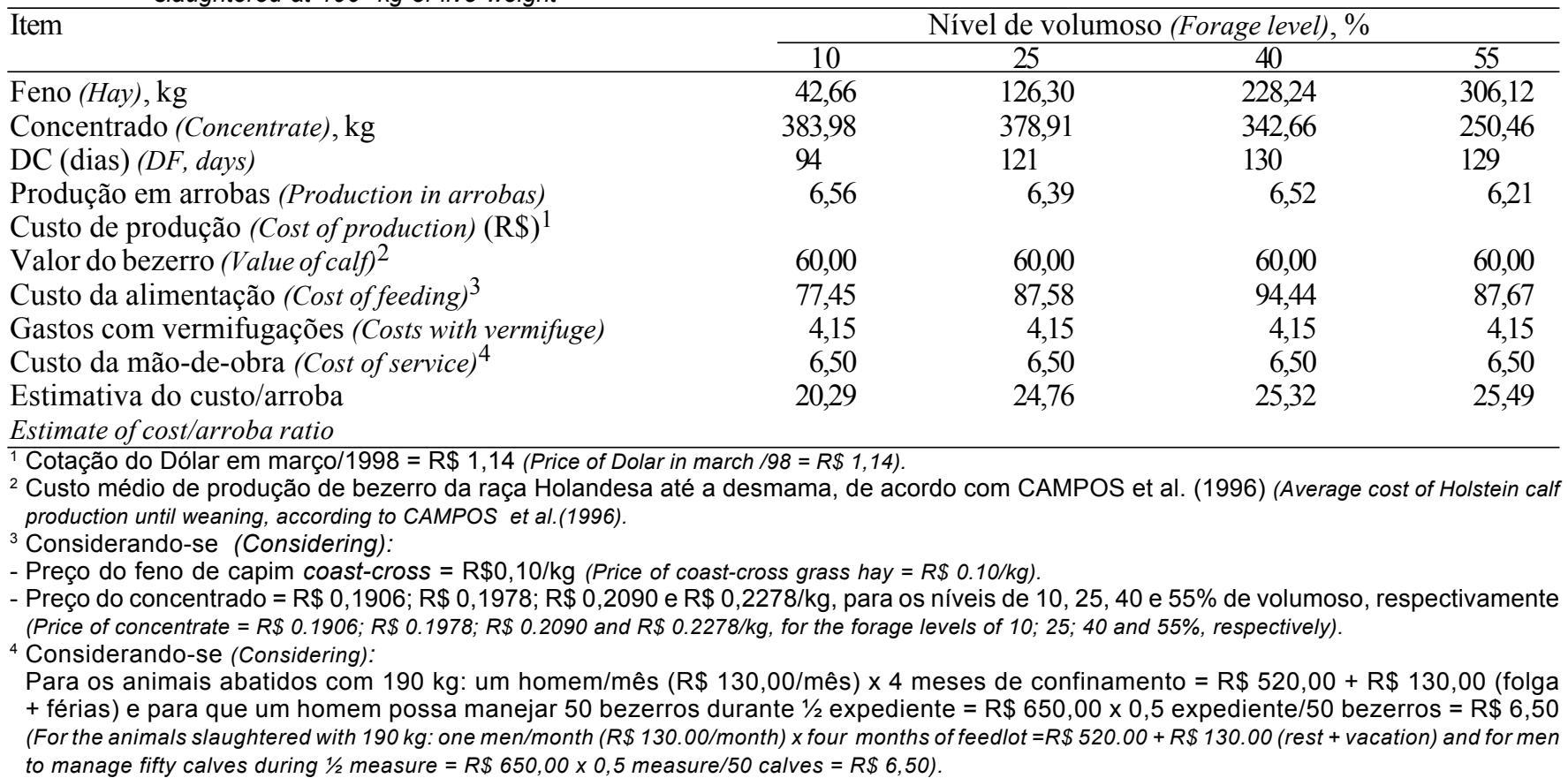

Tabela 4 - Médias de consumo de feno e concentrado, dias de confinamento (DC) e custo de produção por nível de volumoso na dieta de bezerros Holandeses abatidos com $300 \mathrm{~kg}$ de peso vivo

Table 4 - Means of hay and concentrate intake, days of feedlot (DF) and cost of production by forage level in the diet of Holstein calves slaughtered at $300 \mathrm{~kg}$ of live weight

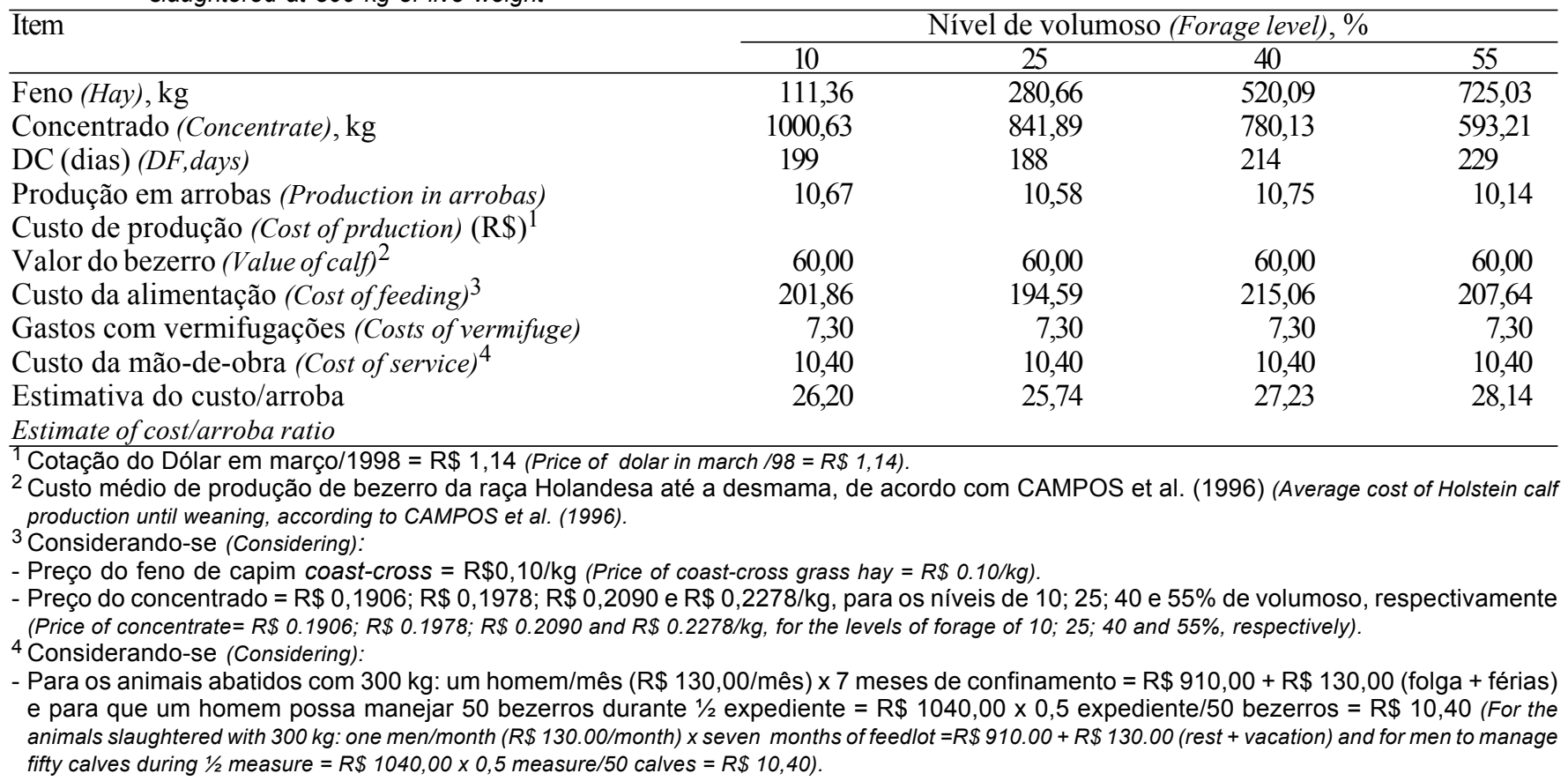


precoce (ROBELIN e GEAY, 1983; GEAY, 1984).

ARAÚJO (1997), trabalhando com rações e animais de faixa etária semelhantes, observou comportamento similar ao encontrado no presente trabalho. $\mathrm{O}$ mesmo autor relatou que a taxa de crescimento écurvilínea e não-linear, em função dos níveis de concentrado na ração. Contudo, a resposta animal à adição de concentrado é variável. Os principais fatores determinantes do ponto ótimo de concentrado na ração foram o sexo, a raça e a idade do animal e a qualidade do volumoso e do concentrado (PRESTON e WILLIS, 1974).

Além disso, animais de maturidade precoce (Raça
Holandesa) e crescimento rápido são mais exigentes, principalmente quanto ao nível de energia na dieta na fase inicial da sua vida, em que as taxas de crescimento ósseo, dos órgãos e muscular são elevadas.

As variáveis GP56 - 84 e GP84-112, para os animais do grupo 1, e GP112 - 140, GP140 - 168, GP168 - 196 e GP196 - 224, para os animais do grupo 2, não foram influenciadas pelo nível de volumoso nas dietas.

Verificou-se tendência de maior ganho diário de peso de 84 - 112 dias de confinamento (GP84 - 112) em animais do grupo 1, com a inclusão de $40 \%$ de volumoso na dieta. Do mesmo modo, para os animais

Tabela 5 - Médias e equações de regressão ajustadas (ER) para ganho diário de peso vivo de 0 - 28 dias (GP0 - 28), 28 - 56 dias (GP28 - 56), 56 - 84 dias (GP56 - 84) e 84 - 112 dias (GP84 - 112), para animais do grupo 1 (190 kg de PV)

Table 5 - Means and fitted regression equations (RE) for daily weight gain from 0 to 28 days, from 28 to 56 days, from 56 to 84 days and from 84 to 112 days, for animals of group 1 (190 kg of LW)

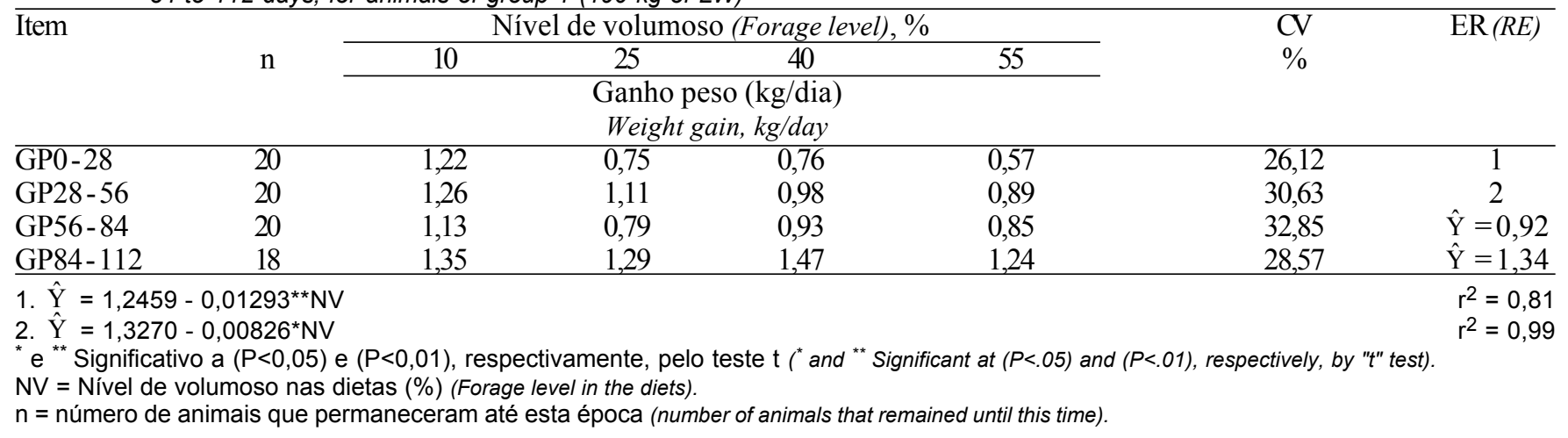

Tabela 6 - Médias e equações de regressão ajustadas (ER), para ganho diário de peso vivo de 0 - 28 dias (GP0 - 28), 28 - 56 dias (GP28 - 56), 56 - 84 dias (GP56 - 84), 84 - 112 dias (GP84 - 112), 112 - 140 dias (GP112 - 140), 140 - 168 dias (GP140 - 168), 168 - 196 dias (GP168 - 196) e 196 - 224 dias (GP196 - 224), para animais do grupo 2 (300 kg de PV)

Table 6 - Means and fitted regression equations (RE) for daily weight gain from 0 to 28 days, from 28 to 56 days, from 56 to 84 days, from 84 to 112 days, from 112 to 140 days, from 140 to 168 days, from 168 to 196 days and 196 to 224 days, for groups 2 (300 kg of LW)

\begin{tabular}{|c|c|c|c|c|c|c|c|}
\hline \multirow[t]{4}{*}{ Item } & \multirow{4}{*}{$\mathrm{n}$} & \multicolumn{4}{|c|}{ Nível de volumoso (Forage level), \% } & \multirow{4}{*}{$\begin{array}{l}C V \\
\%\end{array}$} & \multirow[t]{4}{*}{$\mathrm{ER}(R E)$} \\
\hline & & 10 & 25 & 40 & 55 & & \\
\hline & & \multicolumn{4}{|c|}{ Ganho peso (kg/dia) } & & \\
\hline & & \multicolumn{4}{|c|}{ Weight gain, $\mathrm{kg} /$ day } & & \\
\hline$\overline{\mathrm{GP} 0-28}$ & 16 & 1,06 & 1,17 & 0,85 & 0,73 & 19,65 & 1 \\
\hline GP28 - 56 & 16 & 1,31 & 1,16 & 1,16 & 0,81 & 21,84 & 2 \\
\hline GP56 - 84 & 16 & 1,31 & 1,23 & 0,97 & 0,95 & 17,05 & 3 \\
\hline GP84 - 112 & 16 & 1,28 & 1,17 & 0,96 & 0,92 & 22,46 & 4 \\
\hline GP112 - 140 & 15 & 0,79 & 0,91 & 1,06 & 1,02 & 41,54 & $\hat{\mathrm{Y}}=0,95$ \\
\hline GP140- 168 & 14 & 0,64 & 1,27 & 1,19 & 1,32 & 43,43 & $\hat{\mathrm{Y}}=1,12$ \\
\hline GP168-196 & 14 & 1,28 & 1,48 & 1,42 & 1,22 & 25,43 & $\hat{\mathrm{Y}}=1,35$ \\
\hline GP196-224 & 10 & 0,83 & 1,04 & 0,93 & 0,86 & 26,21 & $\hat{\mathrm{Y}}=0,91$ \\
\hline \multicolumn{7}{|c|}{ 1. $\hat{\mathrm{Y}}=1,2363-0,00874^{* *} \mathrm{NV}$} & $r^{2}=0,72$ \\
\hline \multicolumn{7}{|c|}{ 2. $\hat{Y}=1,4317-0,00994^{\star *} \mathrm{NV}$} & $r^{2}=0,84$ \\
\hline \multirow{2}{*}{\multicolumn{7}{|c|}{$\begin{array}{l}\text { 3. } Y=1,4099-0,00906^{\star *} N V \\
\text { 4. } \hat{Y}=1,3736-0,00886^{\star *} N V\end{array}$}} & $r^{2}=0,89$ \\
\hline & & & & & & & $r^{2}=0,95$ \\
\hline
\end{tabular}


do grupo 2, o ganho diário de peso de 112 - 140 dias de confinamento (GP112 - 140) foi, em média, maior quando os animais receberam dietas com maiores níveis de volumoso. A provável explicação para este fato é que o excesso de concentrado conduz à acidose crônica, refletindo na redução do consumo e contribuindo para ausência de benefícios da utilização de níveis elevados de concentrado em dietas de bovinos em crescimento acima de 100 dias de confinamento. Comportamento semelhante foi encontrado por ARAÚJO (1997).

A partir do exposto acima, para bezerros dessa faixa etária aptos a entrar em confinamento, sugerese que, até os 100 dias de confinamento, ou seja, aproximadamente cinco meses de idade, seja fornecida dieta com maior nível de concentrado (mais energética), porém, acima dessa idade, devese fornecer dietas com maior nível de volumoso de boa qualidade, possibilitando aos animais desempenho considerável (aproximadamente 1,0 kg/dia) e, conseqüentemente, redução substancial dos custos operacionais do confinamento destes animais.

\section{Conclusões}

Os consumos diários de matéria seca não foram influenciados pelos níveis de volumoso nas dieta na faixa de 10 a 55\%, para os animais abatidos aos 190 e $300 \mathrm{~kg}$ de peso vivo.

A CAPV e a CAPCVZ aumentaram, enquanto o GDPV e o GDPCVZ diminuíram linearmente com aumento dos níveis de volumoso nas dietas.

O PCQ não foi influenciado pelos níveis de volumoso para ambos os grupos de animais.

O RCQ para animais abatidos aos $190 \mathrm{~kg}$ apresentou comportamento linear decrescente, enquanto aqueles abatidos com $300 \mathrm{~kg}$ não foram influenciados pelos níveis de volumoso nas dietas.

\section{Referências Bibliográficas}

ARAÚJO, G.G.L. Consumo, digestibilidade, desempenho, composição corporal e exigências nutricionais de bezerros alimentados com dietas contendo diferentes níveis de volumoso. Viçosa, MG: UFV, 1997. 107 p. Tese (Doutorado em Zootecnia) - Universidade Federal de Viçosa, 1997.

BARTLE, S.J., PRESTON, R.L., MILLER, M.F. 1994. Dietary energy sources and density: effects of roughage equivalent, tallow level, and steer type on feedlot performance and carcass characteristics. J. Anim. Sci., 72(8):1943-1953.

BIONDI, P., SCOTT, W.N., FREITAS, E.A.N. et al. 1984. Criação e produção de bovinos machos de raças leiteiras para o corte. Zootecnia, 22(4):281-296.

BROSH, A., AHARONI, Y., LEVY, D. et al. 1995. Effect of diet energy concentration and age of Holstein-Friesian bull calves on growth rate, urea space, and fat deposition, and ruminal volume. J. Anim. Sci., 73:1666-1673.

CAMPOS, O.F. 1994. Estratégias de utilização de bezerros de rebanhos leiteiros para produção de carne. Coronel Pacheco, MG: EMBRAPA/CNPGL (Subprojeto-DPD), 21 p.

CAMPOS, O.F., LIZIEIRE, R.S. Características de dieta do bezerro pré-ruminante. In: IV SIMPÓSIO DO CBNA E III SEMINÁRIO SOBRE TECNOLOGIA DA PRODUÇÃO DE RAÇÕES. Campinas, SP: 1992. p.175 - 196.

CAMPOS, O. F., LIZIEIRE, R.S., ALVES, P.A.P.M. et al. 1996. Experimento do CNPGL/EMBRAPA com abate de machinhos da raça Holandesa aos 6 meses de idade apresenta bons resultados. Gado Holandês, (451):36-45.

CAMPOS, O. F., MATOS, L.L., RODRIGUES A.A. 1991. Bezerros: Quando definir o desaleitamento. Balde Branco, 27(317):24-26.

CAMPOS, O.F., SILVA, A.G. 1986. Fontes alternativas de proteína no sucedâneo do leite para bezerros: revisão de literatura. Pesq. Agropec. Bras., 21(10):1089-1099.

EUCLIDES FILHO, K., EUCLIDES, V.P.B., FIGUEIREDO, G.R. et al. 1997. Avaliação de animais Nelore e seus mestiços com Charolês, Fleckvieh e Chianina, em três dietas. 1. Ganho de peso e conversão alimentar. R. Bras. Zootec., 26(1):66-72.

FEIJÓ, G.L.D., SILVA, J.M., THIAGO, L.R.L. et al. Efeito de níveis de concentrado na engorda de bovinos confinados. Desempenho de novilhos $\mathrm{F}_{1}$ Pardo Suíço x Nelore. In: REUNIÃO ANUAL DA SOCIEDADE BRASILEIRA DE ZOOTECNIA, 31, Fortaleza, CE, 1996. Anais... Fortaleza: SBZ, 1996a. p.73.

FEIJÓ, G.L.D., SILVA, J.M., THIAGO, L.R.L. et al. Efeito de níveis de concentrado na engorda de bovinos confinados. Desempenho de novilhos Nelore. In: REUNIÃO ANUAL DA SOCIEDADE BRASILEIRA DE ZOOTECNIA, 31, Fortaleza, CE, 1996. Anais... Fortaleza: SBZ, 1996b. p.70.

FERREIRA, M.A. Desempenho, exigências nutricionais e eficiência de utilização da energia metabolizável para ganho de peso de bovinos $F_{1}$ Simental x Nelore. Viçosa, MG:UFV, 1997. 97p. Tese (Doutorado em Zootecnia) - Universidade Federal de Viçosa, 1997.

FLUHARTY, F.L., LOERCH, S.C., SMITH, F.E. 1994. Effects of energy density and protein source on diet digestibility and performance of calves after arrival at the feedlot. J. Anim. Sci., 72:1616-1622.

GEAY, Y. 1984. Energy and protein utilization in growing cattle. J. Anim. Sci., 58(3):766-778.

GEAY, Y. Live weight measurement. In: EEC SEMINAR ON CRITERIA AND METHODS FOR ASSESSMENT OF CARCASS AND MEAT CHARACTERISTICS IN BEEF PRODUCTION EXPERIMENTS, 1975, Zeist. Proceedings... s.n.t. p. 35-42.

GOMES, I.P.O, ANDRADE, P. Níveis de substituição de milho por casca de grão de soja na dieta de bovinos. I. Desempenho em confinamento. In: REUNIÃO ANUAL DA SOCIEDADE BRASILEIRA DE ZOOTECNIA, 31, Fortaleza, CE, 1996. Anais... Fortaleza: SBZ, 1996. p.55.

LUCCI, C.S. Alimentos sólidos para bezerros. In: IV SIMPÓSIO DO CBNA E III SEMINÁRIO SOBRE TECNOLOGIA DA PRODUÇÃO DE RAÇÕES. Campinas, SP: 1992. p.196 - 208.

LUCCI, C.S. 1989. Bovinos leiteiros jovens - nutrição - manejo - doenças. São Paulo, SP: NOBEL, 371 p.

MATOS, L.L. Características desejáveis do ambiente para criação de bezerros. In: IV SIMPÓSIO DO CBNA E III SEMINÁRIO SOBRE TECNOLOGIA DA PRODUÇÃO DE RAÇÕES. Campinas, SP: 1992. p.163-173. 
MOLETTA, J.L., RESTLE, J. 1996. Características de carcaça de novilhos de diferentes grupos genéticos terminados em confinamento. R. Soc. Bras. Zootec., 26(5):876-888.

PETIT, H.V., VEIRA, D.M., YU, Y. 1994. Growth and carcass characteristics of beef steers fed silage and different levels of energy with or without protein supplementation. J. Anim. Sci., 72(12):3221-3229.

PRESTON, T.R., WILLIS, M.B. 1974. Intensive beef production. 2. ed. Oxford, Pergamon Press. 546p.

ROBELIN, J., GEAY,Y. 1983. Body composition of cattle as affected by physiological status, breed, sex and diet. In: GILCHRIST, F.M.C., MACKIE, R.I. (Ed). Herbivore nutrition in the subtropics and tropics. The Science Press, Pretoria, South Africa, p.525-548.

SIGNORETTI, R.D., CASTRO, A.C.G., COELHO DA SILVA, J.F. et al. 1995. Utilização do farelo de gérmen de milho no concentrado inicial de bezerros de raças leiteiras em sistema de desaleitamento precoce. R. Soc. Bras. Zootec., 24(5):841 - 851.
SIGNORETTI, R.D., CASTRO, A.C.G., COELHO DA SILVA, J. F. et al. 1997. Avaliação do farelo de gérmen de milho na alimentação de bezerros de raças leiteiras. R. Bras. Zootec., 26(3):616-622.

SIGNORETTI, R. D., COELHO DA SILVA, J. F., VALADARES FILHO, S. C. et al. 1999. Consumo e digestibilidade aparente em bezerros da raça Holandesa alimentados com dietas contendo diferentes níveis de volumoso. Rev. bras. zootec., 28(1):169-177.

Recebido em: 08/04/98

Aceito em: 20/08/98 